\title{
Comparison of efficacy profiles for minimum lethal concentrations (MLCs) of some commonly used commercial hospital microbicidal detergent-disinfectant products for disinfectants and sporicidal activity
}

\author{
Francis Deshaies ${ }^{1}$, Darakhshan Ahmad ${ }^{2}$, Richard Massicotte ${ }^{2}$, Gilbert Pichette ${ }^{1,2}$, \\ Pierre Belhumeur ${ }^{1}$, Mafu Akier Assanta ${ }^{3}$ \\ 'Université de Montréal, Deartment of Microbiology and Immunology Montréal Canada \\ ${ }^{2}$ HSCM-CPRS-LECINO, 5400, boul. Gouin Ouest, Montréal, Canada \\ ${ }^{3}$ Food Research and Development Centre, Agriculture and Agri-Food Canada, QC, Canada
}

doi: 10.3396/ijic.v8i2.013.12

\begin{abstract}
In an effort to evaluate and control the potential hazard and inherent risk of environmental transmission and spread of nosocomial infections by contact with hitherto "non-critical" inanimate/environmental surfaces in the hospital and healthcare facilities (commode, bed, bowl of toilet etc.), the microbicidal efficacies of six disinfectants products commonly used in local hospital facilities was tested. The commercially available detergent-disinfectants (one chlorine-based, one phenol-based, two quaternary ammonium compounds (QACs), generation 3 and generation 4 and, two hydrogen peroxide-based) were evaluated at different concentrations using use-dilution method for evaluating the minimum lethal concentrations (MLCs). Results from these in vitro germicidal exposure experiments indicate that all six disinfectants tested were at the MLCs of these disinfectants in proportion to the recommended strengths varied significantly and yielded very different performance values for different test strains. This knowledge could prove to be of significance in assessing the risks associated with the use, and the incidental failure thereof, of different disinfectants used in the healthcare facilities. The results from our study highlight differences in the activity of germicides against different bacterial strains. These results indicate that the choice of disinfectant agents and the hospital decontamination protocols can markedly affect the prevalence and environmental distribution of pathogens and that this could be better managed if a proper assessment of the risk associated with the use of disinfectants at off-recommended strengths conditions is taken into account in providing guidance towards and seeking satisfactory resolutions to the incidence of breach of manufacturers' recommendations.
\end{abstract}

\section{Corresponding author}

Mafu Akier Assanta

Food Research and Development Centre, Agriculture and Agri-Food Canada, 3600 Casavant Boulevard West, St-Hyacinthe, QC, Canada J2S 8E3 | Tel.: 450-773-7730 ext 138

Email: Akierassanta.mafu@agr.gc.ca 


\section{Key words}

DISEASE TRANSMISSION - infections; CROSS INFECTION - prevention and control; DISINFECTANTS; MICROBIAL SENSITIVITY TESTS

\section{Introduction}

Disinfectants play a vital role in global infection control as a crucial armament against transmission of nosocomial pathogens/ infections combating global disease outbreaks. Recent decades have accumulated a wealth of knowledge on pathogens, pathogen transmission and control of outbreaks of nosocomial infections, disinfection mechanism and disinfectants containing a variety of active antimicrobial ingredients. We have witnessed development of regulatory guidance documents, and commerce of effective detergent-/ disinfectant products with demonstrated efficacy against a broad spectrum of pathogens. However, we still constantly hear of, and duly "acknowledge", the incidence of disease spread/outbreaks due to "insufficient disinfection" incidences. ${ }^{1-5}$

Several reviews and reports clearly reveal, emphasize and establish that indirect transmission via contaminated, "inappropriately decontaminated" or inanimate "noncritical" objects, environmental surfaces plays an important role in nosocomial spread of diseases worldwide. ${ }^{6-9}$ Inappropriate choices and inadequate protocols for the disinfection of inanimate surfaces have been a constant and major source of outbreaks of nosocomial infections. We can not overemphasize that "proper disinfection" is of utmost importance, rather crucial, to interrupt the environmental transmission of pathogens. ${ }^{10-17}$ But why is proper disinfection of these potential environmental surface reservoirs still so difficult?

There are, as well, reports suggesting that subinhibitory levels of disinfectants may induce sporulation and/ or germination of Clostridium difficile spores. ${ }^{1}$ This may be one possible explanation why even with the availability of highly efficient disinfectants the environmental infection transmission is still often not controlled $100 \%$ of the time. Thus, the reasons could be many and varied.

There is quite a variety of liquid chemical disinfectants that are commercially available under a variety of trade names, all tested for their efficacy according to guidance documents developed by various regulatory bodies, worldwide.

During the registration of a disinfectant, regulatory bodies, throughout the world, through their guidelines that manufacturers have to follow, look into efficacy data and labelling details. However, the reality is that in between the manufacturers' detailed directions/ recommendations and the point of use (at the healthcare facilities), a number of risk factors impact the outcomes, the infection control offsets, resulting into nosocomial infection outbreaks, of various nature, of various frequencies, over the board, globally, as the message consistently seems to get lost in transmission/ communications. All marketed products do come with detailed directions for their optimal application and efficient use, and are often sold packaged in concentrated dosage forms with manufacturer recommended working strengths and use-dilution information.

However, from the risk management point of view, the effectiveness range inherent in their use at "off-/beyond-manufacturer-recommended optimal conditions", encountered at the point of use, can not be evaluated unless informative data is available for their efficacies at off-recommended conditions and incidental scenarios. Such as, use of off-recommended concentrations can be envisioned if a disinfectant is not diluted properly and used at below or above the recommended concentration, not applied properly, not stored under appropriate temperature, not kept properly after the stock container is opened, etc.

The intrinsic impact of such possible off-/ beyondrecommended scenarios in the transmission of nosocomial pathogens is difficult to evaluate because of lack of comparative efficacy data for marketed disinfectant products targeted for healthcare facilities.

The present study was undertaken as a first step to generate informative data on off-standard working- 
conditions, using modified microscale versions of European Standard methods (NF EN 1040:2005, NF EN 14347:2005). ${ }^{18,19}$ Suspension tests are often preferred to carrier tests as the bacteria are uniformly exposed to the disinfectant. Six commercially available disinfectants, belonging to four different groups of active ingredients, (phenol-based), (two quaternary ammonium-based), (chlorine-based), and (two hydrogen-peroxide-based), most commonly used in Quebec hospitals and healthcare facilities, were selected for this comparative study. The study was targeted to determine the minimal lethal concentrations (MLCs) of all products against the four selected bacterial species and spores of a clinical isolate of $C$. difficile.

\section{Materials and Methods}

\section{Bacterial Isolates, growth and sporulation media and culture conditions}

Bacterial isolates used in this study were, Staphylococcus aureus (ATCC \#25923), Enterococcus faecalis (ATCC \#19453), Escherichia coli (ATCC \#25922), Pseudomonas aeruginosa (ATCC \#27853) and Clostridium difficile (CD1) (clinical isolate from Honoré-Mercier Hospital, St-Hyacinthe, Quebec, Canada). The culture media and growth conditions were as described in NF EN $1040^{18}$ and NF EN $14347^{19}$ with modifications to adapt the technique to a microscale level.

Precultures were prepared from stock cultures stored at $-80^{\circ} \mathrm{C}$, by streaking on appropriate media plates, then inoculating into liquid TSB (Tryptic Soy Broth) or BHI (Brain Heart Infusion) media and incubation at $37^{\circ} \mathrm{C}$, aerobically or anaerobically as required. The cultures were grown overnight (18-24 hours) in liquid TSB or $\mathrm{BHI}$ media, harvested by centrifugation, washed three times, resuspended in the Tryptone-buffer to an $\mathrm{OD}_{620}$ of $\sim 0.1\left(\sim 5 \times 10^{8}\right.$ cell $\left./ \mathrm{mL}\right)$ using an spectrophotometer and used for bactericidal efficacy assays.

C. difficile was grown anaerobically at $37^{\circ} \mathrm{C}$ for four days in half-strength $\mathrm{BHI}$ to induce sporulation. The spores were harvested, washed twice in cold water and treated at $80^{\circ} \mathrm{C}$ for 10 minutes to kill the vegetative cells according to NF T72-230. ${ }^{20}$ For sporicidal efficacy assays, a spore suspension adjusted to obtain a concentration of $1.4 \times 10^{6}$ spores $/ \mathrm{mL}$ was prepared.

\section{Disinfectants tested}

Six commonly used antimicrobial products of commercial grade from four different groups of active ingredients (one phenol-based, two quaternary ammonium-based, one chlorine-based and two hydrogen-peroxide-based), all sold in concentrated dosage forms, representing different classes of disinfectants, were obtained from the local distributors, (see Table I) hospitals. For quaternary ammonium category, we used two types of product: The generation 3 product is a mixture of equal quantities of a first and second generation of product. The resulting blend provides a greater biocidal activity. ${ }^{21}$ Generation 4 refers to a new mixture of equal parts of didecyl dimethyl ammonium chloride and chloride dioctyl. Generation 4 has a greater germicidal activity to the other three generations, in addition to increased tolerance to environmental conditions: the presence of organics and dilution in hard water. ${ }^{21}$

\section{Microbicidal Efficacy Test /Assay conditions}

Bactericidal and sporicidal efficacy test assays were performed essentially following the protocol described in NF EN1040 ${ }^{18}$ and NF EN $14347^{19}$ albeit at a microscale level using a 96-well microtiter plate. The assays were performed at $20^{\circ} \mathrm{C}$. Each assay mix contained $20 \mu \mathrm{L}$ of bacterial or spore suspension, 20 $\mu \mathrm{L}$ of water and $160 \mu \mathrm{L}$ of the disinfectant. At the end of a given contact time, $20 \mu \mathrm{L}$ of the assay mix was transferred to the second row of wells of the plate containing $20 \mu \mathrm{L}$ of water and $160 \mu \mathrm{L}$ of D/E (DeyEngley broth) neutralizing buffer ${ }^{22}$ (D/E neutralizing buffer proved to be efficient in neutralizing all disinfectant at the highest concentration without affecting the survival of bacterial strains used in this study). After 5 minutes of neutralization period, samples of $20 \mu \mathrm{L}$ of the suspension was plated onto TSA (Tryptic Soy Agar) or BHI plates and incubated for 24 hours at $37^{\circ} \mathrm{C}$ under required conditions.

For initial bacterial counts, serial dilutions of the initial bacterial or spore suspension were plated on TSA or $\mathrm{BHI}$ plates and incubated under required conditions. Colonies forming units (cfu) per plate were recorded and the log reduction values were determined to evaluate the bactericidal/ sporicidal efficacy under different assay setups. The assays were done in duplicated and repeated three times. For determining 
Table II. Dilutions of the disinfectants used to determine the MLCs for bactericidal activity

Disinfectant product used

Chlorine-based

Phenole-based

Quaternary Ammonium $3^{\text {rd }}$ generation

Quaternary Ammonium $4^{\text {th }}$ generation

Accelerated Hydrogen Peroxide-based Bactericide

Accelerated Hydrogen Peroxide-based Tuberculocide
Dilutions \%

$$
\begin{aligned}
& 0.65,0.31,0.15,0.078 \\
& 0.70 .0 .35,0.18,0.90 .0 .43 \\
& 0.05,0.024,0.012,0.006 \\
& 0.025,0.012,0.006,0.003 \\
& 0.78,0.39,0.19,0.097 \\
& 6.25,3.12,1.56,0.78
\end{aligned}
$$

the MLCs were significantly different among the six disinfectants tested. As presented in Table 4, the phenol based disinfectant seems to be the least effective as the $5 \log$ reduction was not observed against all bacterial strains at $>8$-fold dilution of the working concentration (equivalent to $48: 13 \mathrm{mg} / \mathrm{L}$ ). The two QAbased disinfectants were the most effective at 64-fold dilution (equivalent to $19 \mathrm{mg} / \mathrm{l}$ and $6 \mathrm{mg} / \mathrm{l}$, respectively) against three of the bacterial strains, and showed even better efficacy against $P$. aeruginosa at 128-fold dilution of the recommended working concentration (equivalent to $10 \mathrm{mg} / \mathrm{L}$ and $3 \mathrm{mg} / \mathrm{L}$, respectively).

The chlorine based disinfectant showed good effectiveness with an MLC corresponding to 64-fold dilution of the recommended level (equivalent to $82 \mathrm{mg} / \mathrm{L}$ ) against three strains, and a MLC of 32-fold dilutions (equivalent to $164 \mathrm{mg} / \mathrm{L}$ ) for $E$. faecalis. The MLC levels for the two accelerated hydrogen peroxide based disinfectants, exhibited greater variation in efficacy against different test strains, although the trends were similar. The MLC values were the highest (least effective) for $E$. coli with 16-fold dilution of the recommended level (equivalent to $195 \mathrm{mg} / \mathrm{L}$ ) for the accelerated hydrogen peroxide based bactericide.
However, the other accelerated hydrogen peroxide based disinfectant (tuberculocide) showed very good efficacy against $S$. aureus, with 128-fold dilution of the recommended level (equivalent to $39 \mathrm{mg} / \mathrm{L}$ ). Interestingly, the accelerated hydrogen peroxidebased tuberculocide product always showed stronger efficacy than its counterpart with a 2 times higher dilution required to achieve MLC.

In order to give a better idea of the efficacy of disinfectants, their efficacies against four different bacterial strains were compared. Data presented in Table $\mathrm{V}$ clearly demonstrate that the phenol based disinfectant was equally effective against 3 strains and least effective on $P$. aeruginosa. Activated hydrogen peroxide based disinfectants were both most effective on S. aureus and least against E. coli. QA-based generation 4 and generation 3 disinfectants were both most effective on $P$. aeruginosa and equally effective against the other three test strains. Chlorine based solution was equally effective against $E$. coli, P. aeruginosa, $S$. aureus and least effective on $E$. faecalis.

The in vitro germicidal exposure test data for the sporicidal efficacy of the six disinfectants against

Table III. Dilutions of the disinfectants used to determine the MLCs for sporicidal activity

\section{Disinfectant product used}

Chlorine-based

Phenole-based

Quaternary Ammonium $3^{\text {rd }}$ generation

Quaternary Ammonium $4^{\text {th }}$ generation

Accelerated Hydrogen Peroxide-based Bactericide

Accelerated Hydrogen Peroxide-based Tuberculocide
Dilutions

$$
\begin{aligned}
& 0.100^{*}, 0.050 .0 .025,0.012 \\
& 0.014,0.007^{*}, 0.003,0.001 \\
& 0.031,0.016^{*}, 0.008,0.004 \\
& 0.016,0.008^{*}, 0.004,0.002 \\
& 0.125,0.062 *, 0.031,0.15 \\
& 1.000^{*}, 0.500 .0 .250 .0 .125
\end{aligned}
$$

* Manufacture recommended working strength concentrations 
spores of $C$. difficile, presented in Table VI, indicate that only the chlorine based disinfectant, was sporicidal at almost all dilutions in the series of dilutions tested, up to 64 -fold dilution (equivalent to $82 \mathrm{mg} / \mathrm{L}$ ), except the last dilution in the series tested, 128-fold dilution (equivalent to $41 \mathrm{mg} / \mathrm{L}$ ), where bacterial growth was observed. None of the other five disinfectants showed any sporicidal activity against spores of $C$. difficile at all concentrations tested, even at concentrations higher than the recommended levels, including the activated hydrogen peroxide based disinfectants.

\section{Discussions and Conclusions}

Our results demonstrate significant differences in microbicidal efficacies of the disinfectants tested at a range of concentrations that include higher and lower than recommended working conditions, information that could be useful in evaluating risk associated with incidences of "improper decontamination" of healthcare environment. Indeed, some disinfectants such as the phenol-based products loose their efficacy with only a few dilutions (see Table IV).

This is particularly important considering the fact that the efficiency of disinfectants vary greatly depending on nature of the surface being disinfected, number and nature of microorganisms present, presence of organic soil, duration of exposure and temperature. ${ }^{9-13}$ So, applying liquid disinfectants on the surface, in the right concentration, contact time and environment (temperature) is probably not a guarantee of success. Some other important issues regarding "improper decontamination" procedure based on difference between actual/ in-house/ onsite practice and recommended protocols may also accentuate the problem. Some disinfectants such as activated hydrogen peroxide-based disinfectant may not be suitable for all kinds of pathogens, since a lot of variability of efficacy was observed in our study regarding this particular class of disinfectant. Moreover, Table V clearly demonstrates that pathogens are not equally sensitive to disinfectant products. This emphasizes even more on the importance of choosing the right disinfectant for the right situation (such as, specific disease spread or outbreaks).

The data from the sporicidal efficacy tests of the six disinfectants indicate that only the chlorine based disinfectant, was sporicidal at 64-fold dilution (equivalent to $82 \mathrm{mg} / \mathrm{L}$ ). These results corroborate with those obtained by Fawley etal. that among 5 commercial detergent/cleaning agents and/or germicides (3 chlorine-based, 1 nonionic detergent, and 1 hydrogen peroxide based: Chlor-clean, Sanichlor, Dispatch, Hospec, G-Force, respectively) only the chlorine based disinfectants were sporicidal against the spores of 6 strains of $C$. difficile at working concentrations. ${ }^{1}$ All 5 product tested, including the detergent, in their study did inhibit the growth of vegetative cells of $C$. difficile not only at recommended working concentration but at concentrations several folds lower than the recommended strengths. We did similar experiments and the results clearly suggested that the vegetative form was very sensitive to all the disinfectants used since there was a remarkable decrease in bacterial growth with all disinfectants tested (data not shown). Other groups like Perez et al. also reported acidified bleach and regular bleach (3000-5000 ppm) to be sporicidal against $C$. difficile spores. ${ }^{23}$ None of the other five of the six disinfectants tested in our study showed any sporicidal activity against spores of $C$. difficile at all concentrations tested, even at concentrations higher than the recommended levels, including peroxide based disinfectants. Oxidizing microbicides has been shown to be sporicidal against spores of several strains of $C$. difficile and B. subtillis at 7000ppm within 10-15 minutes tested under quantitative carrier test method, ${ }^{23}$ a method implying much greater challenge than those used in our study.

There is a variety of disinfectants (approved and certified by appropriate governmental / regulatory agencies) available in the market. However, these disinfectants contain/ belong to different groups of chemical compounds, active pharmaceutical ingredient (API), and are sold in different dosage forms (ready to use or concentrates to be diluted (fresh) and once open, shelf life has to be respected, etc.). In addition, the technical staffs that actually use these disinfectants are not trained/ well informed of their mode of action and importance of their chemical nature and their intended use, in order to make a knowledge based decision.

In fact, even the professionals and technical staffs do not have enough detailed knowledge of the MICs and MLCs of different marketed disinfectants vis-à-vis atuse concentration, as such comparative information is altogether absent. This has an implication on the 
Table IV. Classification of disinfectants according to their efficacy against various bacteria

\begin{tabular}{|c|c|c|c|c|}
\hline $\begin{array}{l}\text { Bacterial } \\
\text { species }\end{array}$ & Disinfectant products & $\begin{array}{r}\text { Manufacturer } \\
\text { recommended } \\
\text { concentrations } \\
(\mathrm{mg} / \mathrm{L})\end{array}$ & $\begin{array}{r}\text { MLCs of the product } \\
(\mathrm{mg} / \mathrm{L})\end{array}$ & $\begin{array}{r}\text { Disinfectant efficacy } \\
\text { Fold dilution required } \\
\text { from manufacturer } \\
\text { recommended } \\
\text { concentrations to } \\
\text { achieve MLCs }\end{array}$ \\
\hline \multirow{6}{*}{ E. coli } & Phenol based ${ }^{1}$ & $380: 100$ & $48: 13$ & $8 x$ \\
\hline & $\begin{array}{l}\text { Activated hydrogen peroxide } \\
\text { based }\end{array}$ & 3125 & 95 & $16 x$ \\
\hline & $\begin{array}{l}\text { Activated hydrogen peroxide } \\
\text { based tuberculocide }\end{array}$ & 5000 & 1563 & $32 x$ \\
\hline & Quat gen 4 & 1184 & 19 & $64 x$ \\
\hline & Quat gen $3^{2}$ & $360: 360$ & $6: 6$ & $64 x$ \\
\hline & Chlorine based & 5250 & 82 & $64 x$ \\
\hline \multirow{6}{*}{ E. faecalis } & Phenol based ${ }^{1}$ & $380: 100$ & $48: 13$ & $8 x$ \\
\hline & $\begin{array}{l}\text { Activated hydrogen peroxide } \\
\text { based }\end{array}$ & 3125 & 98 & $32 x$ \\
\hline & $\begin{array}{l}\text { Activated hydrogen peroxide } \\
\text { based tuberculocide }\end{array}$ & 5000 & 78 & $64 x$ \\
\hline & Quat gen 4 & 1184 & 19 & $64 x$ \\
\hline & Quat gen $3^{2}$ & $360: 360$ & 6 & $64 x$ \\
\hline & Chlorine based & 5250 & 164 & $32 x$ \\
\hline \multirow{6}{*}{ P. aeruginosa } & Phenol based ${ }^{1}$ & $380: 100$ & $48: 13$ & $8 x$ \\
\hline & $\begin{array}{l}\text { Activated hydrogen peroxide } \\
\text { based }\end{array}$ & 3125 & 98 & $32 x$ \\
\hline & $\begin{array}{l}\text { Activated hydrogen peroxide } \\
\text { based tuberculocide }\end{array}$ & 5000 & 78 & $64 x$ \\
\hline & Quat gen 4 & 1184 & 9 & $128 x$ \\
\hline & Quat gen $3^{2}$ & $360: 360$ & $3: 3$ & $128 x$ \\
\hline & Chlorine based & 5250 & 82 & $64 x$ \\
\hline \multirow{6}{*}{ S. aureus } & Phenol based ${ }^{1}$ & $380: 100$ & $48: 13$ & $8 x$ \\
\hline & $\begin{array}{l}\text { Activated hydrogen peroxide } \\
\text { based }\end{array}$ & 3125 & 49 & $64 x$ \\
\hline & $\begin{array}{l}\text { Activated hydrogen peroxide } \\
\text { based tuberculocide }\end{array}$ & 5000 & 39 & $\begin{array}{r}128 x \\
64 x\end{array}$ \\
\hline & Quat gen 4 & 1184 & 19 & $64 x$ \\
\hline & Quat gen $3^{2}$ & $360: 360$ & 6 & $64 x$ \\
\hline & Chlorine solution & 5250 & 82 & \\
\hline
\end{tabular}

Note: Contact time was 5 minutes.

${ }^{1}$ Clorophene: O-phenylphenol

${ }^{2}$ Alky dimethyl ethyl bezyl ammonium chloride: Benzalkonium chloride 


\section{Table V. A preview of data on MLCs of the tested disinfectants}

\begin{tabular}{|c|c|}
\hline Disinfectant products & $\begin{array}{l}\text { Comparative sensitivity of different bacterial strains } \\
\text { in regard to disinfectant products (based on MLCs) }\end{array}$ \\
\hline Phenol based & E. coli $=E$. faecalis $=S$. aureus $=P$. aeruginosa \\
\hline Peroxide hydrogene & S. aureus $>E$. faecalis $=P$. aeruginosa $>E$. coli \\
\hline $\begin{array}{l}\text { Peroxide hydrogene } \\
\text { tuberculocide }\end{array}$ & $S$. aureus $>$ E. faecalis $=P$. aeruginosa $>E$. coli \\
\hline Quat gen 4 & P. aeruginosa $>E$. coli $=E$. faecalis $=S$. aureus \\
\hline Quat gen 3 & P. aeruginosa $>E$. coli $=E$. faecalis $=S$. aureus \\
\hline Chlorine solution & E. coli $=P$. aeruginosa $=S$. aureus $>E$. faecalis \\
\hline
\end{tabular}

standard operating protocols (SOPs), if these do exist, at the point of use locations, and if actually followed, and if audits are made for their proper use/ application, especially under the ever-increasing use of Healthcare facilities with increased workloads and/or decreased number of staff, and increasing technological and material variety and resources available to deal with. Under such scenarios where an estimate of the situation /risk is not possible to reach, one ideally intends to consider each situation as the worst possible case/ condition, in order to ensure the goal of disinfecting all types of materials, all types of microorganisms/ pathogens, all levels of soil/ organic matter, etc.

However, there is challenge inherent to such a practice as well. Not all disinfectant groups manifest same level of efficacies on different groups of organisms/ pathogens, for different levels of organic matter/ soil, on different types of surfaces, and these technical details / information are not available to professionals/decision makers on purchase of products for their facilities and/ or to guide and instruct the actual user because of the datagap(s). In an attempt to shed light/provide insight and fill in useful information into this datagap, as an initial first step, for an efficient (effective, appropriate, safe and economical) use of surface disinfectant at their point of use in healthcare institutions, we have started an on-going study at the HSCM-CPRS (Hospital of Sacré-Coeur de Montreal-Centre provincial de référence en stérélisation).

The work presented here is an initial first set of data from an in vitro comparative study on bactericidal efficacies of 6 different disinfectant products used in healthcare facilities in Quebec, targeted to determine their MLCs vis-à-vis their recommended use concentrations and contact times. CPRS, a Quebec's provincial reference centre in sterilization (not mandated for all disinfections) is inundated with requests seeking advice for real life situations at the hospitals where an intelligent decision has to be made, sometimes based on limited information available from the scientific literature. Scarcity of such data or total datagaps, must be filled in with studies that are informative and of practical use, with ease of implication in real life scenarios, by the decision makers. A lot of work by the researchers and scientists in the field of disinfectants done for decades has culminated into guidance documents; there is still lack of data available for in-use/ on-site situations for making informed science-based decisions for local point of use applications. Our results demonstrate significant differences in microbicidal efficacies of these disinfectants at a range of concentrations and contact times that include higher and lower than recommended working conditions, information that could be useful/exploited in evaluating risk associated with incidences of "improper decontamination" of healthcare environment.

\section{Acknowledgements}

The authors would like to thank the Groupe d'hygiène et salubrité at Hôpital Sacré-Cœur de Montréal as well as the Service des activités de soutien et du partenariat of the Ministère de la Santé et des Services sociaux du Québec for their financial support, which made this project possible. 


\section{Table VI. Sporicidal efficacy profiles of various disinfectants against C. difficile spores ${ }^{1}$ at different concentrations}

\section{Disinfectant products}

Chlorine-based

(Free chlorine 5.25\%)
Concentration (mg/L)

$5250^{*}$

2625 ( $2 x$ dilution)

1312 (4x dilution)

656 (8x dilution)

328 (16x dilution)

164 (32x dilution)

82 (64x dilution)

380:100*

Phenole-based)
41 (128x dilution)
(Clorophene 5.45\%: O-phenylphenol $1.47 \%)$

760 : 200 (double strength)

190 : 50 (2x dilution)

95 : 25 (4x dilution)

$360: 360^{*}$

Quaternary Ammonium $3{ }^{\text {rd }}$ generation (Alky dimethyl ethyl bezyl ammonium chloride $2.25 \%$ : Benzalkonium chloride $2.25 \%$ )

$720: 720$ (double strength)

180 : 180 (2x dilution)
90 : 90 (4x dilution) Bacterial Growth

\section{$1184^{*}$}

2368 (double strength)

592 (2x dilution)

296 (4x dilution)

$3125^{*}$

Peroxide

6250 (double strength)

(AHP 0.5\% )

1562 (2x dilution)

781 (4x dilution)

$5000^{*}$

Peroxide tuberculocide

2500 ( $2 x$ dilution)

(AHP 0.5\%)

1250 (4x dilution)

625 (8x dilution)

$+$

$+$ $+$ $+$ $+$ $+$ $+$

*Manufacture-recommended Use-Dilution concentration.

1 Bactericidal efficacy was also tested on the vegetative form of C. difficile, but the presence of spores in the cell suspension made the interpretation of the result difficult. However, the results clearly suggested that the vegetative form was very sensitive to all the disinfectants used since there was a remarkable decrease in bacterial growth with all disinfectants tested (data not shown). 


\section{References}

1. Fawley WN, Underwood S, Freeman J et al. Efficacy of hospital cleaning agents and germicides against epidemic Clostridium difficile strains. Infect Control Hosp Epidemiol 2007; 28(8): 920-925. http://dx.doi.org/10.1086/519201

2. Mafu AA, Roy D. Disinfecting and Sterilizing agents used in food industry. In: Labbé RG, García S, Eds. Guide to Foodborne Pathogens, $1^{\text {st }}$ edn. New York, NY: A John Wiley Sons, Inc. 2001; 315-332.

3. Hota B. Contamination, disinfection, and cross-colonization; are hospital surfaces reservoires for nosocomial infection? Clin Infect Dis 2004; 39(8): 1182-1189. http://dx.doi. org/10.1086/424667

4. Gastmeier P, Stamm-Balderjahn S, Hansen S et al. How outbreaks can contribute to prevention of nosocomial infection: Analysis of 1,022 outbreaks. Infect Control Hosp Epidemiol 2005; 26(4): 357-361. http://dx.doi. org/10.1086/502552

5. Heeg P, Roth K, Reichl R, Cogdill CP, Bond WW. Decontaminated single-use devices: an oxymoron that may be placing patients at risk for cross-contamination. Infect Control Hosp Epidemiol 2001; 22(9): 542-549. http://dx.doi. org/10.1086/501949

6. Spaulding EH. Chemical disinfection of medical and surgical materials. In: Block SS, Lawrence CA, eds. Disinfection, sterilization, and preservation. Philidelphia: Lea \& Febiger. 1968; 517-531.

7. Rutala WA, Weber DJ. Disinfection and sterilization in health care facilities: what clinicians need to know. Clin Infect Dis 2004; 39(5): 702-709. http://dx.doi.org/10.1086/423182

8. Rutala WA, Weber DJ. The benefits of surface disinfection. Am J Infect Control 2005; 33(7): 434-435. http://dx.doi. org/10.1016/j.ajic.2004.12.007

9. Weber DJ, Rutala WA. Use of germicides in the home and the healthcare setting: is there a relationship between germicide use and antibiotic resistance? Infect Control Hosp Epidemiol 2006; 27(10): 1107-1119. http://dx.doi.org/10.1086/507964

10. Boone SA, Gerba CP. Significance of fomites in the spread of respiratory and enteric viral diseases. Appl Environ Microbiol 2007; 73(6): 1687-1696. http://dx.doi.org/10.1128/ AEM.02051-06

11. Mafu, AA, Lemay MJ, Montpetit D. Evidence for Escherichia coli O157:H7 attachment to water distribution pipe materials by scanning electron microscopy. J Food Prot 2002; 65(12): 1970-1975.
12. Cozad A, Jones RD. Disinfection and the prevention of infectious disease. Am J Infect Control 2003; 31(4): 243-254. http://dx.doi.org/10.1067/mic.2003.49

13. Fawley WN, Freeman J, Smith C, et al. Use of highly discriminatory fingerprinting to analyze clusters of Clostridium difficile infection cases due to epidemic ribotype 027 strains. J Clin Microbiol 2008; 46(3): 954-960. http:// dx.doi.org/10.1128/JCM.01764-07

14. Dvorak G. 2005. Disinfection 101. The Center for Food Security and public Health, lowa State University. http:// www.cfsph.iastate.edu/BRM/resources/Disinfectants/ Disinfection101Feb2005.pdf [Accessed Novembre 1 ${ }^{\text {st }}$ 2011]

15. Hugo WB. A brief history of heat and chemical preservation and disinfection. J Appl Bacterio/ 1991; 71(1): 9-18.

16. Manangan LP, Pugliese G, Jackson M, et al. Infection control dogma: top 10 suspects. Infect Control Hosp Epidemiol 2001; 22(4): 243-247. http://dx.doi.org/10.1086/501894

17. Springthorpe VS, Sattar SA. Carrier tests to assess microbicidal activities of chemical disinfectants for use on medical devices and environmental surfaces. J AOAC Int 2005; 88(1):182201.

18. NF EN 1040 (T 72-152): Chemical disinfectants and antispetics. Quantitative suspension test for the evaluation of basic bactericidal activity of chemical disinfectants and antiseptics. Test method and requirements (phase 1). Brussels, 2005.

19. NF EN 14347: Chemical disinfectants and antiseptics. Basic sporicidal activity. Test method and requirements (phase 1, step 1). Brussels, 2005.

20. NFT72-230: Water miscible and neutralisable antiseptics and disinfectants used in liquid form - Determination of sporicidal activity (dilution-neutralisation method) - Brussels, 1988.

21. Massicotte $\mathrm{R}$, Groupe en hygiène et salubrité, Hygiène et salubrité en milieux de soins - Démarche pour le développement de stratégies d'entretien des surfaces, Ministère de la Santé et des Services sociaux du Québec, 2010; 77p.

22. Engley Jr FB, Dey BP. A universal neutralizing medium for antimicrobial chemicals. In: Prindle RF ed. Proceedings of the 56th Mid-year Meeting of the Chemical Specialties Manufacturers Association.New York, NY: Chemical Specialties Manufacturer's Association, Inc. 1970; 100-106.

23. Perez J, Springthorpe VS, Sattar SA. Activity of selected oxidizing microbicides against the spores of Clostridium difficile: Relevance to environmental control. Am / Infect Control 2005; 33(6): 320-325. http://dx.doi.org/10.1016/j. ajic.2005.04.240 